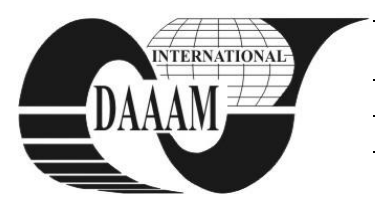

Annals of DAAAM for 2012 \& Proceedings of the 23rd International DAAAM Symposium, Volume 23, No.1, ISSN 2304-1382 ISBN 978-3-901509-91-9, CDROM version, Ed. B. Katalinic, Published by DAAAM International, Vienna, Austria, EU, 2012 Make Harmony between Technology and Nature, and Your Mind will Fly Free as a Bird Annals \& Proceedings of DAAAM International 2012

\title{
DEVELOPING AND IMPLEMENTING A NEW VISUAL MONITORING SYSTEM FOR MACHINING
}

\author{
REIBENSCHUH, M[arko]; ZUPERL, U[ros] \& CUS, F[ranci]
}

\begin{abstract}
Quality is in machining usually defined with the surface quality of the machined part. The main influence comes from the selected cutting conditions - parameters. Monitoring of these parameters and the influence of them can be determined with different methods and systems. In this paper the development and application of a new monitoring system, based on visual detection, is described. The used equipment and software is outlined. Primary purpose of the system is to visually detect any problems or events improper for the selected cutting process. A program for insert and chip detection is developed and tested. Results are given and guidelines for further work are laid.
\end{abstract}

Keywords: milling, monitoring, vision control, chip formation, tool wear

\section{INTRODUCTION}

Implementing the use of hardware and software applications into machining is already well-established [1, 4, 5, 6, 8 and 9]. Different approaches [2, 3, 12 and 13] are used and many different parameters are observed during machining [7, 10, 11 and 14]. This includes force measurements, vibration and temperature measurements as well as vision control. On behalf of gathered results, some authors use artificial intelligence [7, 11 and 12] for off line optimization and afterward applying the optimized data into the machining process. For on line respectively in line optimization, the algorithms are for now, to slow. In line [6] optimization runs in slow or medium speed applications, where the systems has enough time to gather, evaluate, compute and present the results. Researchers apply different methods as artificial intelligence and special programs to achieve improvements in machining methods. The methods improve following properties:

- End quality of the work piece,

- Tool life expectancy,

- Detection of damages to the work piece or tool,

- Lowering production costs,

- Speeding up the production.

Usually more than one of the above mentioned properties can be improved at the same time. The reason is the correlation between different factors. The end quality of the work piece is correlated to feed rate. Feed rate is correlated to cutting forces and this again to tool life expectancy. The relations are proven by many researchers and their papers. Furthermore almost every researcher goes his own way of defining the correlations and setting the rules for optimization. In such a spirit the new system was developed to supplement and outperform the old system and further increases the monitoring of machining systems.
In our laboratory we mainly concentrate on researching the cutting conditions during milling. This includes end milling and plain milling. Less attention is devoted to side milling because it is used mostly for rough machining. The quality of end finishing is for now satisfying, but there is still space for improvements. Especially in tool life expectancy and in determination of chip formation a lot of options are available. Reviewing up to date research [1-14], a decision was made to implement a visual monitoring of cutting conditions. It includes visual inspection of tools, work piece, chip formation as well as measurements of all three. The chip formation is at high feed rates very distinctive for a certain type of material and it is quite easy to be visual detected. The most importante information is the chip length, width and color. On behalf of these, the cutting conditions can be determined. It explains what the cutting conditions are during at a specific time in machining and what parameters need to be adjusted to change/improve results as surface roughness and tool wear.

The best possible results, when milling a work piece, are short, broken of chips. Such chips enable the fastest material removal rate and in this process the cutting tool and the work piece are cooled - overheating is prevented. If it occurs because of drastical increase in cutting parameters, the overheating can damage the tool and the work piece. Life expectancy of the tool is drastically shortened and the work piece is at the given area hardened and brittle, making it useless for further work or use. Therefore in some cases cutting fluids are used. But they cannot be used for every application. Dry cutting is sometimes more useful. Also the cost for cutting fluids mostly exceeds the cost of additional tool (inserts) and therefore it is economically more suitable and sustainable to use additional tools.

The new monitoring system is adapted to milling and special programs were developed to monitor the conditions during machining. Testing's are subordinated to determine the range of use of the applied camera and what possibilities it offers for other applications.

\section{CHOSING COMPONENTS FOR TESTING}

For work piece material a special hard steel alloy was chosen, because of its hardness. The hardness of the material ranged from 60 to 64 HRC. Dry cutting conditions were chosen. Cutting fluid is not suitable for vision applications because the camera need a clear side of view - the cutting fluid blurs the view. 
The used camera is a product of National Instrument, a Smart Camera 1772C (1772C). The maximum output is 64,995 frames per second (fps). An additional camera was also used. This one is from the manufacturer Basler, type acA640. Its maximum output is at $110 \mathrm{fps}$. The $1772 \mathrm{C}$ has also all the connectors to connect it to a PC, external lightning, external monitor and a RS 232 port whereas the acA640 lack these conections. Over the external connection it is possible to connect a LED light source to the $1772 \mathrm{C}$ and light the observed area of interest. The options in light settings were set to strobe mode. This mode enables that the light turns on just in the right moment as the camera takes the frame. The intensity of the light is also higher because higher amperage can be set. On continuous light, the maximum can be set at $500 \mathrm{~mA}$, at strobe mode, this value can be set to $1 \mathrm{~A}$. The light is not a single LED diode, but it is an assembled ring light consisting of 24 separate LED's.

The main difference between cameras is in it adjustments possibilities. The $1772 \mathrm{C}$ has a lot of options including the most useful ones:

- Setting the light conditions - driver for external light, - Setting the color of the gathered frames - RGB or monochrome.

The Basler camera does not support such settings, furthermore it's speed requires a very capable computer with fast processing abilities. Namely the speed of the frame acquisition is for normal computers too fast. Special adaptations are needed for the computer to save and process all the data. SATA 2 ports are physically too slow. It is not the size of the gathered frames that presents a problem but the size respectively the number of frames per second. All the data must be transfered to the PC via Giga Ethernet cable. There the 110 files need to be saved. Because every second another 110 frames arrive, the buffer of the computer fills up and consequently the camera slows down - the frame rate begins to fluctuate. A focus on one specific point is not possible.

The 1772C also possesses its own buffer and so enables to store all gathered frames without a delay in observation. It also has a built in processor. The $1772 \mathrm{C}$ can be used autonomously or connected to a PC via Ethernet port.

The cutting parameters were set to a medium value for a certain type of milling tool.

\begin{tabular}{|l|l|}
\hline Diameter of the cutting tool & $100 \mathrm{~mm}$ \\
\hline Number of Inserts & 5 \\
\hline Maximum cutting speed & $6500 \mathrm{rpm}$ \\
\hline Medium cutting speed & $3250 \mathrm{rpm}$ \\
\hline
\end{tabular}

Tab. 1. Cutting parameters and tool data

The cutting speed was calculated from the diameter of the tool and the rotations of the spindle.

The software part (feature recognition program) of the whole system was developed in LabVIEW. LabVIEW enables lot of options and combinations for using the $1772 \mathrm{C}$. In the first settings, the program was set to detect the insert of the cutting tool and a change in the proximity of the cutting tool - chip formation. Next version was used to detect if there is an insert in the specified field of interest and if it is detected, in what condition (shape/size) it is. Programing is enabled with different blocks, from which everyone has its own properties and settings. Only with extensive tests and trials, one can determine the proper sequences of programing. But which ones to use are entirely dependent of the monitoring needs and the programmer.

\section{PREPARATIONS FOR TESTING}

Considering the cutting speed of $3250 \mathrm{rpms}$, the tool rotates 54.17 times in a second. To match this value, the value for exposure time and gain was adapted so that the camera captures the same amount of frames - a frame was captured every $0.0185 \mathrm{~s}$. These settings were set in the program Measurement \& Automation Explorer. The values on the machine were set to $3250 \mathrm{rpm}$ and a feed rate was chosen according to the tool. Various lighting conditions were tested before the right one was chosen. Also some modifications were needed to the whole setup of tool, work piece and equipment, to prevent light reflection and figure distortion.

For an accuracy of $0.1 \mathrm{~mm}$ there are some area limitations. The observed area is $640 \times 480$ pixels which is equivalent to $21.3 \times 16 \mathrm{~mm}$. For higher or lower values, a new calculation must be made and other settings need to be adjusted. In this case, for insert and chip monitoring, the observed area is just right.

Dry cutting conditions were chosen. This option enables perfect view into the working zone. The use of cutting fluid would make it very hard to detect anything but the cutting fluid spraying around.

The test setup is shown in Fig. 1. Because the camera has no auto focus, this was preset manually.

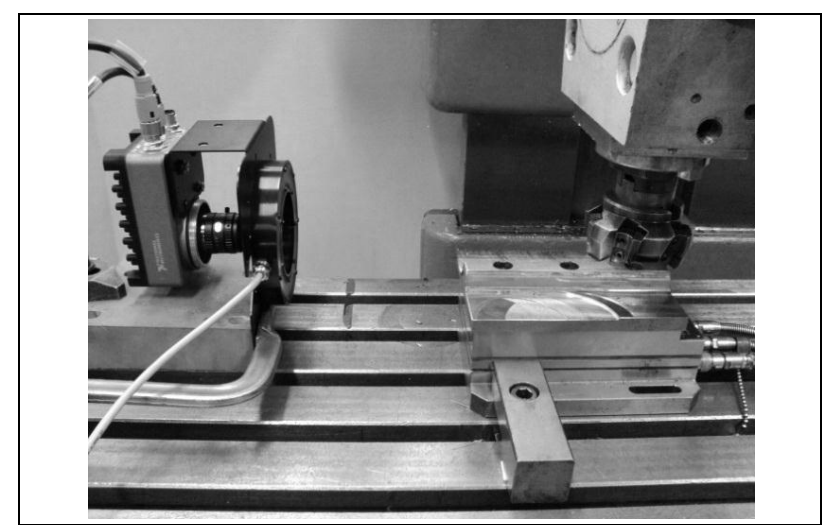

Fig. 1. Experimental setup

During the testing some issues were raised about the focus of the camera. For further testing a holder is being developed, which will enable a constant distance to the cutting tool and in doing so, enable sharp frames during the whole testing.

\section{RESULTS}

Initial results gathered during the first cut, were used to assess the situation in the cutting zone and to develop 
a feature recognizing software. The frames acquired during the test are shown in Fig. 2.

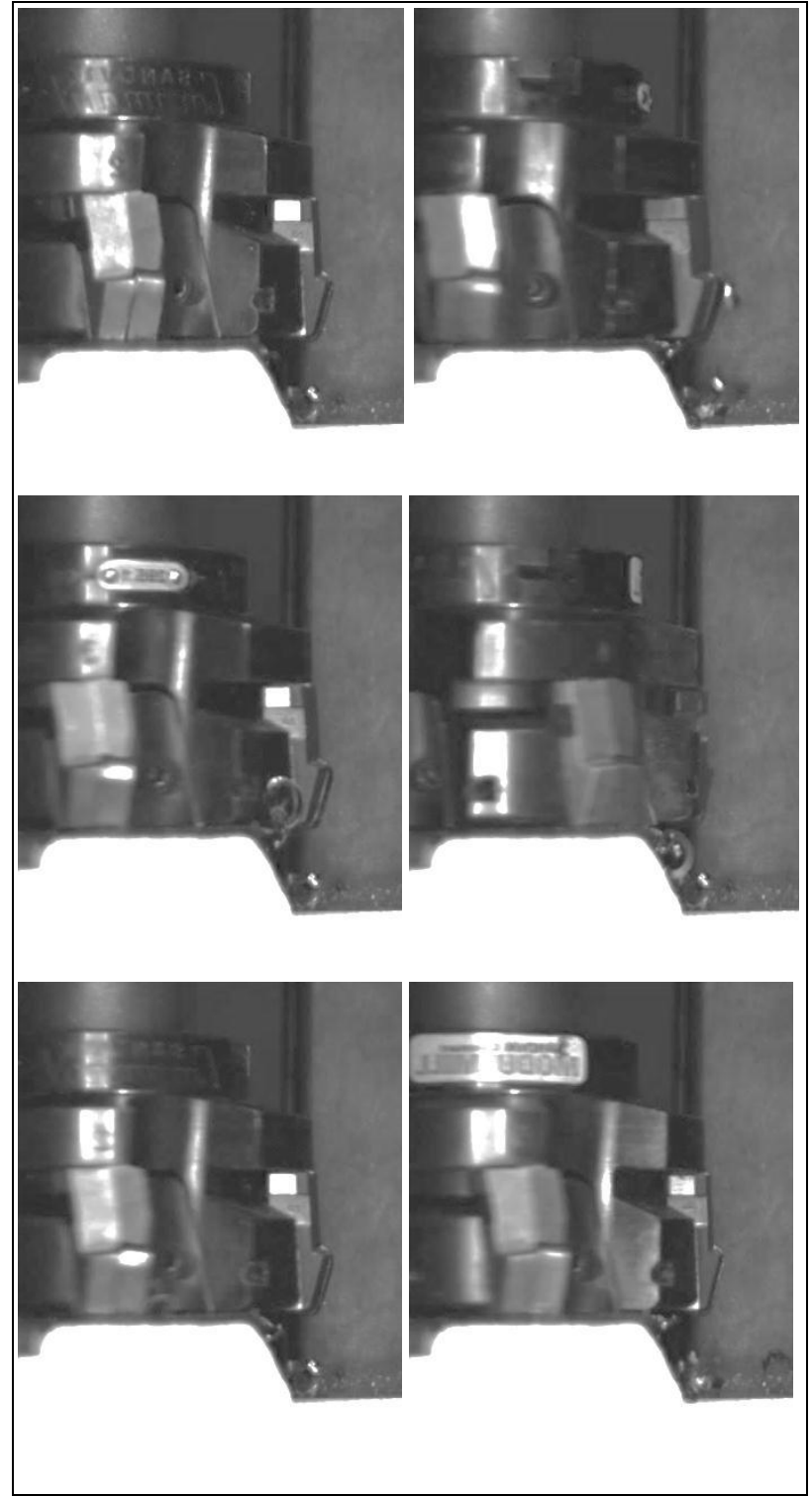

Fig. 2. Gathered frames for developing a program

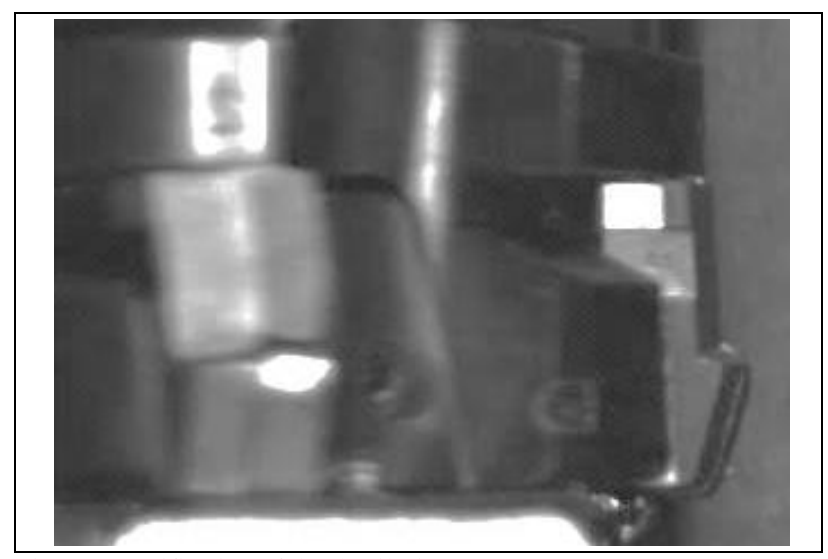

Fig. 3. Magnification of the detail - insert

Fig. 3 shows the magnified insert of the cutting tool. To detect the presence of the insert, the size and the shape of it, some additional programs are needed. All of the programing was conducted in LabVIEW 2011, where some new options are available. Depending on the cutting conditions and the frame quality, also color deviations can be monitored.

Fig. 4 shows how the program works - detection of insert and taking action (recognition, measurements, classification...). In this step, the insert was recognized and measured. Other options can be added to determine the chip size and chip wear.

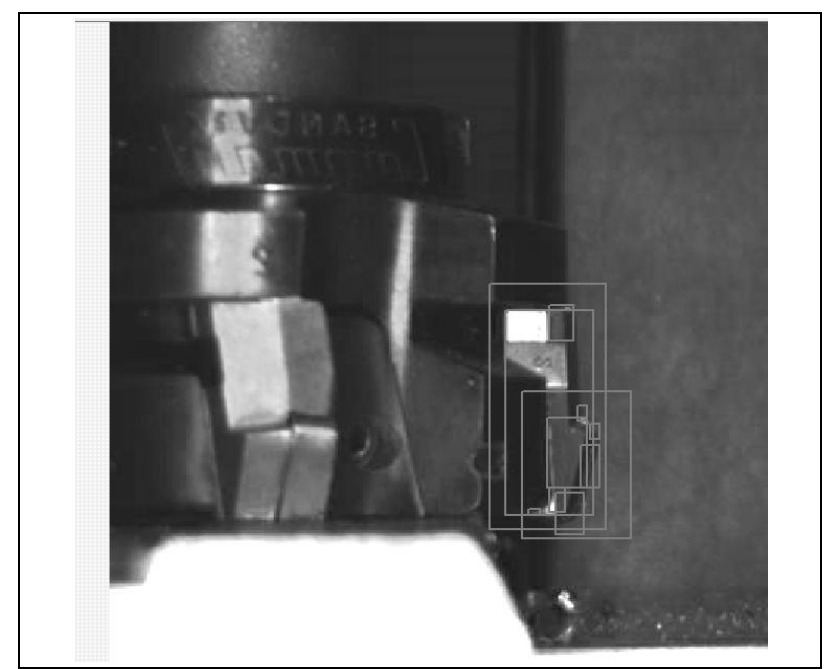

Fig. 4. Detection of insert

Insert detection is whit this program and hardware combination possible. Fig. 5 shows chip detection. The bigger circle represents the area of interest - the area where the camera respectively the program searches for a change or familiar shape. When such a change is detected, the smaller circle appears the chip is detected. Now the program classifies the chip according to preset values. It is also capable ob measuring the chip and on behalf of those measurements makes a conclusion on current cutting conditions. The program is similar to the one for insert detection but it has some additional filters and filter settings, logic calculators etc. which allows the detection of different shapes and sizes. Fig. 6 shows how a chip is detected and measured during its flight from the shear zone. A mesh appears and the whole broken off chip is measured. If the chip is too small, then the cutting parameters are not suitable for cutting such a material. Also visible are the already broken off chips which are not remowed from the area of interest. In such a case, those already detected chips can present problems. In such cases the best options is to clean the work piece with air.

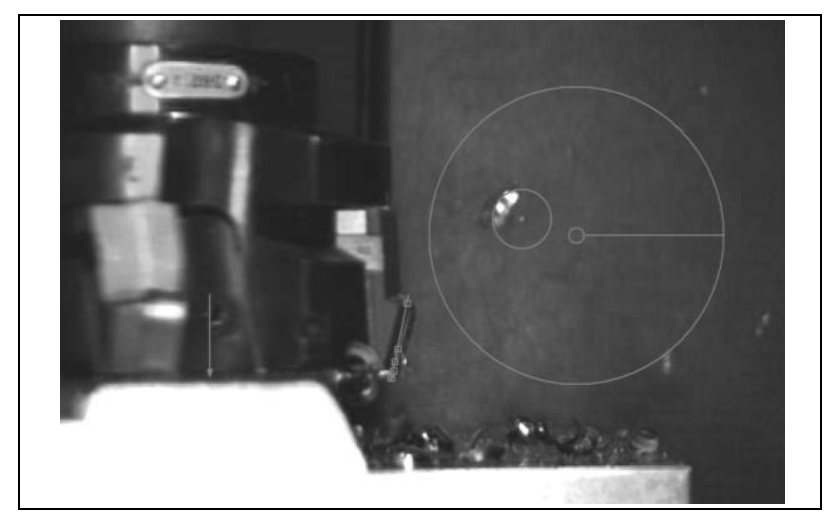

Fig. 5. Software development - chip detection 


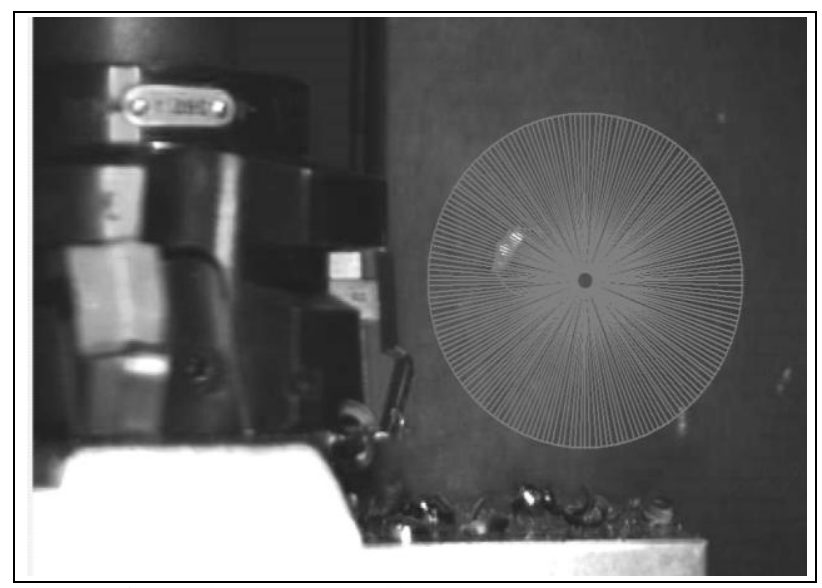

Fig. 6. Software development - chip measurement

Different display options are available and depending on the search criteria, these options can be highlighted.

\section{CONCLUSION}

Using the combination of high speed camera and software development, a reliable monitoring system is established. It enables the detection of different features, which are directly linked to current cutting conditions and consequently to the quality of the whole production process. The next advantage is the option of combining it with other monitoring systems such as vibration and force measurements. Because of the systems relative low demands for computer power, different applications can be run on a single computer. But for more complex observations, monitoring and data processing in real time a more capable computer is needed. During the research work some interesting information came to light. Although almost every computer theoretically sufficiently meets the calculated demands for data transfer rate and processor power (for test purposes used computer - HP ProBook 4520s, i5 processor, 4GB RAM and $400 \mathrm{~GB}$ disk), in praxis it fails.

For further work additional programs (insert wear/measurements, tool measurements, work piece inspection,...) and tests will be conducted to evaluate the usability of such a monitoring approach. The monitoring system will also be applied to other cutting procedures (drilling, turning and grinding) to evaluate the option of developing a single program for different machine operations. The use of additional cameras is being also evaluated.

\section{REFERENCES}

[1] Mulc, T.; Udiljak, T.; Ciglar, D.; Brezak, D. \& Staroveski, T. (2010). Application of Non-Parametric Methods for Monitoring of Tool Chipping, Annals of DAAAM for 2010 \& Proceedings of the 21st International DAAAM Symposium, 20-23rd October 2010, Zadar, Croatia, ISSN 1726-9679, ISBN 978-3-901509-735, Katalinic, B. (Ed.), pp. 0297-0298, Published by DAAAM International Vienna, Vienna

[2] Constantin, C.; Bisu, C. - F.; Croitoru, S. M. \& Constantin, G. (2010). Milling Analysis by 3D FEM and Experimental Tests, Annals of DAAAM for 2010 \& Proceedings of the 21st International DAAAM Symposium, 20-23rd October 2010, Zadar, Croatia, ISSN 1726-9679, ISBN 978-3-901509-73-5, Katalinic, B. (Ed.), pp. 0337-0338, Published by DAAAM International Vienna, Vienna
[3] Fabian, M.; Spisak, E.; Seminsky, J.; Senderska, K.; Mares, A. \& Izol, P. (2010). CAM Parameters Settings and NC Milled Surface Quality, Annals of DAAAM for 2010 \& Proceedings of the 21st International DAAAM Symposium, 20-23rd October 2010, Zadar, Croatia, ISSN 1726-9679, ISBN 978-3-901509-73-5, Katalinic, B. (Ed.), pp. 0391-0392, Published by DAAAM International Vienna, Vienna

[4] Daraba, D. \& Boca, G. D. (2010). Experimental Assessment of the Milling Machine Column Before Remanufacturing, Annals of DAAAM for 2010 \& Proceedings of the 21st International DAAAM Symposium, 20-23rd October 2010, Zadar, Croatia, ISSN 1726-9679, ISBN 978-3-901509-73-5, Katalinic, B. (Ed.), pp. 0733-0734, Published by DAAAM International Vienna, Vienna

[5] Tangjitsitcharoen, S. \& Rungruang, C. (2010). Investigation of Cutting Conditions with Dry Cutting and Applications of Cutting Fluid for Ball-End Milling Process, Annals of DAAAM for 2010 \& Proceedings of the 21st International DAAAM Symposium, 20-23rd October 2010, Zadar, Croatia, ISSN 1726-9679, ISBN 978-3-901509-73-5, Katalinic, B. (Ed.), pp. 1385-1386, Published by DAAAM International Vienna, Vienna

[6] Tangjitsitcharoen, S. \& Senjuntichai, A. (2010). In-Process Monitoring and Prediction of Surface Roughness in Ball-End Milling Process, Annals of DAAAM for 2010 \& Proceedings of the 21st International DAAAM Symposium, 20-23rd October 2010, Zadar, Croatia, ISSN 1726-9679, ISBN 978-3-901509-735, Katalinic, B. (Ed.), pp. 1389-1390, Published by DAAAM International Vienna, Vienna

[7] Zuperl, U.; Cus, F. \& Balic, J. (2010). Neural Network Based Control Algorithm in Robotised Unmanned Flexible Manufacturing System, Annals of DAAAM for 2010 \& Proceedings of the 21st International DAAAM Symposium, 2023rd October 2010, Zadar, Croatia, ISSN 1726-9679, ISBN 9783-901509-73-5, Katalinic, B. (Ed.), pp. 0305-0306, Published by DAAAM International Vienna, Vienna

[8] Tangjitsitcharoen, S. \& Pongsathornwiwat, N. (2010). In-Process Monitoring and Detection of Chatter in Milling Process on CNC Machining Center, Annals of DAAAM for 2010 \& Proceedings of the 21st International DAAAM Symposium, 20-23rd October 2010, Zadar, Croatia, ISSN 1726-9679, ISBN 978-3-901509-735, Katalinic, B. (Ed.), pp. 1387-1388, Published by DAAAM International Vienna, Vienna

[9] Grigorescu, C. - M.; Moraru, S. - A. \& Badea, M. (2010). Smart Data Acquisition Software Used in Industrial Monitoring Systems, Annals of DAAAM for 2010 \& Proceedings of the 21st International DAAAM Symposium, 20-23rd October 2010, Zadar, Croatia, ISSN 1726-9679, ISBN 978-3-901509-73-5, Katalinic, B. (Ed.), pp. 0103-0104, Published by DAAAM International Vienna, Vienna

[10] Sysel, M. (2010). Remote Control and Monitoring in the Simulink, Annals of DAAAM for 2010 \& Proceedings of the 21st International DAAAM Symposium, 20-23rd October 2010, Zadar, Croatia, ISSN 1726-9679, ISBN 978-3-901509-73-5, Katalinic, B. (Ed.), pp. 0205-0206, Published by DAAAM International Vienna, Vienna

[11] Cus, F.; Zuperl, U. \& Gecevska, V. (2009). Self-Learning Control Strategy with Application to Milling System, Annals of DAAAM for 2009 \& Proceedings of the 20th International DAAAM Symposium, 25-28th November 2009, Vienna, Austria, ISSN 1726-9679, ISBN 978-3-901509-70-4, Katalinic, B. (Ed.), pp. 0451-0452, Published by DAAAM International Vienna, Vienna

[12] Kromanis, A. \& Krizbergs, J. (2009). Prediction of Surface Roughness in End-Milling using Fuzzy Logic and its Comparison to Regression Analysis, Annals of DAAAM for 2009 \& Proceedings of the 20th International DAAAM Symposium, 2528th November 2009, Vienna, Austria, ISSN 1726-9679, ISBN 978-3-901509-70-4, Katalinic, B. (Ed.), pp. 0803-0804, Published by DAAAM International Vienna, Vienna

[13] Dixit P. M. (2008) Modeling of metal forming and machining processes: by finite element and soft computing methods, Springer, London

[14] Xu C., Chen H., Liu Z., Cheng Z., Condition monitoring of milling tool wear based on fractal dimension of vibration signals, 2009, Strojniški vestnik - Journal of Mechanical Engineering 55 (2009), Vol. 1, pp. 15-25 